\title{
Aging of different avian cultured cells: Lack of ROS-induced damage and quality control mechanisms
}

\author{
Valentina Strecker ${ }^{\mathrm{a}}$, Sören Mai ${ }^{\mathrm{a}}$, Britta Muster ${ }^{\mathrm{a}}$, Sascha Beneke ${ }^{\mathrm{b}}$, Alexander Bürkle ${ }^{\mathrm{b}}$, \\ Jürgen Bereiter-Hahn ${ }^{a}$, Marina Jendrach ${ }^{\mathrm{a}, *}$ \\ ${ }^{a}$ Kinematic Cell Research Group, Institute for Cell Biology and Neuroscience, Center of Excellence Frankfurt: Macromolecular Complexes, Goethe University, \\ Max-von-Laue-Str. 9, 60438 Frankfurt/Main, Germany \\ ${ }^{\mathrm{b}}$ University of Konstanz, Faculty for Biology, LS Molecular Toxicology, Box X911, D-78457 Konstanz, Germany
}

\author{
Keywords: \\ Birds \\ Aging \\ ROS \\ Autophagy \\ ATG5 \\ Compensatory proliferation
}

\begin{abstract}
A B S T R A C T
Elevated reactive oxygen species (ROS) levels have been observed in mammals during aging, implying an important role of ROS in the aging process. Most bird species are known to live longer and to contain lower ROS levels than mammals of the same body weight. The influence of ROS on the aging process of birds has been investigated using pigeon embryonic fibroblasts (PEF) and chicken embryonic fibroblasts (CEF). ROS levels in young avian cells were much lower than in human cells. When cultivated till replicative senescence, PEF proliferated about one-third longer compared to CEF. However, both senescent avian cell populations showed no increased ROS levels or accumulation of ROS-induced damage on the mtDNA or protein level. The investigation for quality control (QC) mechanisms revealed that the autophagosomal/lysosomal pathway was not downregulated in old avian cells and stable overexpression of the autophagy protein ATG5 improved mitochondrial fitness, enhanced the resistance against oxidative stress and prolonged the life span of CEF. Oxidative stress-mediated apoptosis induced a dose-dependent cell proliferation in CEF as well as in PEF. Taken together, our data indicate that autophagy and compensatory proliferation act as QC mechanisms, while ROS did not influence the aging process in avian cells.
\end{abstract}

\section{Introduction}

The maximal live span potential (MLSP) of most bird species, e.g. pigeons, parakeets or canaries is higher than the MLSP of mammals with a similar body weight (Barja, 1998; Holmes and Ottinger, 2003). The reasons for the extended life span of birds started to emerge recently and seem to be at least partly connected with the load of reactive oxygen species (ROS). ROS are considered as one of the primary factors in the aging of mammals (Dufour and Larsson, 2004; Lu and Finkel, 2008) and interestingly, mitochondria from long-lived birds produce significantly less ROS in comparison to mitochondria of mammals with the same body size (Ku and Sohal, 1993; Barja et al., 1994). Furthermore, long-lived birds and also avian cells

Abbreviations: BSO, buthionine sulfoximine; CEF, chicken embryonic fibroblasts; DHE, dihydroethidium; DHR, dihydrorhodamine; GPX4, glutathione peroxidase 4 LSM, laser scanning microscopy/microscope; MLSP, maximal live span potential; mtDNA, mitochondrial DNA; PD, population doublings; NAC, N-acetylcysteine; QC, quality control; PEF, pigeon embryonic fibroblast; ROS, reactive oxygen species; SOD, superoxide dismutase.

* Corresponding author. Tel.: +49 69 79829605; fax: +49 6979829607.

E-mail address: jendrach@bio.uni-frankfurt.de (M. Jendrach). show increased resistance to oxidative stress in comparison to mammalian models (Barja and Herrero, 1998; Ogburn et al., 1998, 2001).

These data lead to the hypothesis that in avian cells the accumulation of ROS-induced damage would be slower due to the low ROS levels, resulting in the enhanced MLSP of birds (PerezCampo et al., 1998). Recent data imply that damaged mitochondrial DNA (mtDNA) is sufficient to induce aging (Trifunovic et al., 2004,2005 ) and it seems possible that in avian cells a low rate of free radical production would result in a very gradual mtDNA damage. In accordance with this hypothesis a previous study demonstrated that the oxidative DNA damage marker 8-oxo-7,8dihydro-2'-deoxyguanosine was reduced in brain and heart mtDNA of long-lived bird species when compared to the mtDNA of short-lived mammals (Herrero and Barja, 1999). Taken together, data obtained till now link longevity of birds to a low oxidative load, but how this is achieved is still unclear. An efficient system of enzymatic and non-enzymatic scavenging mechanisms could be responsible for the low ROS levels in birds. In addition, quality control (QC) mechanisms as mitochondrial dynamics (fission and fusion), autophagy and apoptosis can keep the amount of damaged, increasingly ROS-producing mitochondria low and influence the aging process. (Tatsuta and Langer, 2008). 
To approach the question how ROS are influencing the aging process of avian cells and which QC mechanisms are important, a long-lived bird species was compared to a short-lived one. Due of the huge physiological and genetic differences between birds and mammals, this seemed more appropriate than the comparison of birds and mammals. Birds that are either unable to fly at all or weak flyers have a shorter live span than good flyers (Holmes and Austad, 1995) and according to the free radical hypothesis of aging (Harman, 1972) non-flyers/weak flyers should exhibit higher ROS levels and increased ROS-induced damage.

Thus, we compared the in vitro aging process of embryonic fibroblasts that were derived from chicken as model for a non-flying, short-lived species and pigeon as a representative of a well-flying, long-lived avian species. Interestingly, both senescent populations showed no increased ROS levels or ROS-induced damage, indicating that ROS are of minor or no importance in the in vitro aging of cultured avian cells. Furthermore, our data indicate that compensatory proliferation and autophagy act as QC mechanisms in proliferating avian cells, thus probably contributing to the extended life span of birds without influencing the ROS levels.

\section{Materials and methods}

\subsection{Cultivation of cells}

Chicken (white leghorn) eggs (virus-free) were obtained from Charles River Laboratories and pigeon (carrier pigeon) eggs were obtained from R. Wiltschko (Zoological Institute, Goethe University, Frankfurt, Germany). Leg tissue of 10-day-old embryos was homogenized and cells were separated by incubation with $0.1 \%$ trypsin for $20 \mathrm{~min}$ at $37^{\circ} \mathrm{C}$. A homogenous cell population was obtained after filtration (filter with $60 \mu \mathrm{m}$ pores). Cells were cultivated for two passages until a fibroblast culture was obtained. Each culture contained cells from three different animals to minimize the influence of genetic factors. For maintenance cells were kept at $41^{\circ} \mathrm{C}$ (Rattan and Buchanan, 1982) with $5 \% \mathrm{CO}_{2}$ and $95 \%$ air in IMDM (Invitrogen) with $5 \%$ FCS (Invitrogen), 5\% chicken serum (Invitrogen) and 1\% penicillin/streptomycin (Invitrogen) in flasks that had been coated with $0.2 \%$ gelatin (Sigma).

Population doublings (PD) were determined using the following equation: $\mathrm{PD}=3.32 \times(\log 10 \mathrm{UCY}-\log 10 I)+X$, where $\mathrm{UCY}$ is the number of cells at the end of the passage; $I$ the number of cells that were seeded at the beginning of the passage and $X$ the previous PD number. The percentage of senescencent cells was determined by staining cells with the Senescence Cells Histochemical Staining Kit (Sigma) (Dimri et al., 1995), according to the manufacturers instructions.

HeLa cells were cultured at $37^{\circ} \mathrm{C}$ in Minimal Essential Medium with Earle's salts (Invitrogen) containing 10\% FCS and 1\% MEM non-essential amino acids (Invitrogen)

\subsection{Generation of stable transfected CEF}

The ORF of gATG5 (NM_001006409) was amplified by RT-PCR from chicken cDNA with the primers listed under RNA isolation and semiquantitative RT-PCR and cloned into the EcoRI and BamH1 sites of the vector EGFP C1 (Clontech). The resulting construct was verified by sequencing. The CMV promotor and either GFP or GFPgATG5 were amplified by PCR and cloned into the Clal site of the RCAS A vector, a retroviral vector that had been derived from the SR-A strain of Rous sarcoma virus (Federspiel and Hughes, 1997). The resulting plasmids were transfected with Effectene (Qiagen) into young CEF according to the manufactures instructions. One week after transfection almost all cells showed GFP fluorescence, indicating stable transfection/infection of the whole cell population with recombinant virus.

\subsection{Determination of telomere length}

Chromosome isolation for Quantitative Fluorescence In Situ Hybridization (QFISH): cells in $75 \mathrm{~cm}^{2}$-flasks were treated with $0.01 \mathrm{mg} / \mathrm{ml}$ colcemide (Life Technologies) for $1 \mathrm{~h}$ to stall mitosis. Then, the supernatant was removed and stored. Adherent cells were harvested by trypsin treatment, pooled with the supernatant and spun down at $200 \mathrm{~g}$ for $5 \mathrm{~min}$ at RT. Afterwards, cells were washed $1 \times$ with PBS. Fixation was essentially done as described in (Mai et al., 2002). Fixed cells were stored at $-20^{\circ} \mathrm{C}$.

Q-FISH analysis and evaluation: Q-FISH analysis was done essentially as described before (Lansdorp et al., 1996) Metaphase spreads on Superfrost slides (VWR, Germany) were hybridized to Cy3-labelled PNA-telomere probes (Dako Cytomation, Denmark), counterstained with DAPI and analyzed with a fluorescence microscope (Zeiss Axiovert) using Axiovision software (Zeiss, Germany). Telomere signal intensities were analyzed with TeloQuant (Dako Cytomation, Denmark). The median of telomeric signal intensities from at least 250 chromosomes was determined and experiments were performed in independent triplicates.

\subsection{Confocal laser scanning microscopy}

To determine the mitochondrial morphology cells were stained with Mitotracker Deepred (Molecular Probes; final concentration $25 \mathrm{nM}$ ) for $1 \mathrm{~h}$ or TMRE (Molecular Probes; final concentration $100 \mathrm{nM}$ ) for $30 \mathrm{~min}$. For visualization of F-actin cells were fixed and stained for $20 \mathrm{~min}$ with FITC-Phalloidin (Sigma, $2 \mu \mathrm{l} / \mathrm{ml}$ ). For staining of mtDNA cells were treated with Picogreen (Molecular Probes), final dilution 1:100. To visualize lysosomes, cells were stained for $30 \mathrm{~min}$ with Lysotracker Green (Molecular Probes; final concentration $50 \mathrm{nM}$ ). Stained cells were observed with a Leica TCS SP5 confocal laser scanning microscope (LSM) equipped with the appropriate filters and HCX PL APO lambda blue 63.0 $\times, 1.40$ OIL UV and HCX PL APO 63.0×, 1.30 GLYC $37{ }^{\circ} \mathrm{C}$ UV objectives that were controlled by the LAS AF scan software (version 1.8.2) (Leica, Germany). Live cell experiments were performed at $37{ }^{\circ} \mathrm{C}$ and $5 \% \mathrm{CO}_{2}$ in a humidified chamber. Pictures visualized with IMARIS 6.0.0 (BITPLANE Scientific solutions).

\subsection{Quantification of the ROS content (DHE and DHR staining)}

The determination of ROS was achieved by staining cells with dihydrorhodamine 123 (DHR; Molecular Probes; final concentration $20 \mu \mathrm{M}$ ) for $30 \mathrm{~min}$ or with dihydroethidium (DHE; Molecular Probes; final concentration $5 \mu \mathrm{M}$ ) for $30 \mathrm{~min}$. Pictures of the fluorescent samples were taken with constant microscopical settings and the micrographs were analyzed using the program Imagej, to evaluate the integrated fluorescence of rhodamine or ethidium. To determine the relative fluorescence intensity for each micrograph, each grey value was multiplied with the respective amount of pixels. The total sum of these products was divided by the total sum of pixels. The highest relative fluorescence intensity was always set to $100 \%$. For the measurement of the DHE content by FACS (Becton Dickinson), cells were stained for $30 \mathrm{~min}$ with DHE (final concentration $20 \mu \mathrm{M}$ ), and directly after trypsinisation analyzed by flow cytometry.

\subsection{High-resolution respirometry}

Mitochondrial respiratory parameters of endothelial cells were measured by high-resolution respirometry using the Oroboros ${ }^{\mathbb{B}}$ oxygraph $2 \mathrm{k}$ (for details see, e.g. Hutter et al., 2006). $3 \times 10^{6}$ Cells were used for each the measurement. During the measurement cells were kept in growth medium at $41^{\circ} \mathrm{C}$. For the inhibition of complex V $2 \mu \mathrm{g} / \mathrm{ml}$ oligomycine were used (final concentration $2 \mathrm{ng} / \mathrm{ml}$ ) and complex I was blocked by addition of rotenone $(0.5 \mu \mathrm{g} / \mathrm{ml}$, final concentration $0.25 \mathrm{ng} / \mathrm{ml}$ ).

\subsection{Oxyblot}

$1 \times 10^{6}$ Cells were resuspended in a lysis buffer containing $50 \mathrm{mM}$ sodium phosphate buffer (pH 7,8), $150 \mathrm{mM} \mathrm{NaCl}, 1 \%$ deoxycholate (Na-based), $0.1 \%$ SDS, 2 mM EDTA, $2 \% \beta$-mercapotoethanol. The Oxyblot was performed with the OxyBlot Protein Oxidation Detection Kit (Chemicon) according to the manufacturer's instructions. Proteins of young and old CEF and PEF were separated on the same gel, then transferred onto a nitrocellulose membrane by semidry blotting and blocked for $2 \mathrm{~h}$ in $1 \%$ PBSTM ( $1 \%$ milk, $0.1 \%$ tween 20 ). Incubations with the first and second antibody were performed in PBST. For detection of the bands the SuperSignal West Femto Maximum Sensitivity Substrate (Thermo) and a Molecular Imager ChemiDoc XRS (Biorad) was used. For determination of total protein levels 150,000 lysed cells were separated on a $12 \%$ SDS/polyacrylamide gel and total protein content was visualized by Coomassie Blue staining. The quantification of the respective grey values of both gels was achieved with the program Image and the amount of oxidized protein was normalized on the total protein content.

\subsection{Quantification of lysosomal activity}

The lysosomal activity was quantified by determining the activity of acid phosphatase, a key enzyme of the lysosomes. Experiments were performed in triplicates in a 96 well plate. Cells were trypsinizied and counted. 300,000 cells were lysed in the lysis buffer used for oxyblotting (see above) and added to the substrate provided with the Acid Phosphatase Assay Kit (Sigma). After 30 min incubation at $37{ }^{\circ} \mathrm{C}$ the absorbance of the p-nitrophenol was determined at $405 \mathrm{~nm}$ in an ELISA reader (Tecan).

\subsection{Quantification of $m t D N A$}

Total DNA was isolated from $1 \times 10^{6}$ CEF with the DNA Flexi Kit (Qiagen). A $220 \mathrm{bp}$ and an $8.2 \mathrm{~kb}$ fragment of mtDNA were amplified by semiquantitative PCR according to Santos et al. (2002). Primers were designed based on the sequence of the complete mitochondrial genome of Gallus gallus (NC_001323.1); primers for the small fragment (222 bp) were $5^{\prime}$-TGCCAACCTTCATCTCACCATAACC-3' (sense; 14,778-14,802) and 5' -TTTCATCAAGCAGAGATGTTGGATGG-3' (antisense; 15,000$14,975)$ and for the large fragment ( $8251 \mathrm{bp}$ ) $5^{\prime}$-ACTTAGCCTTCTAATTCGCGCAGA-3' (sense; 6749-6772) 5'-TTTCATCAAGCAGAGATGTTGGATGG-3' (antisense; 15,00014,975). After gel electrophoresis quantification of ethidium bromide stained PCR products was archived with Easywin 32 software (Herolab). 


\subsection{RNA isolation and semiquantitative RT-PCR}

Total RNA was isolated from 1 to $3 \times 10^{6} \mathrm{CEF}$ with Trizol (Invitrogen), according to the manufacturers instructions. $2 \mu \mathrm{g}$ of total RNA were used for first strand synthesis with oligo(dT) and random hexamer primers. Expression of gATG5 mRNA and scavenging enzyme transcripts was analyzed in a semiquantitative PCR, with $\beta$ actin for normalization.

Primer: $\beta$-actin: 5'-CCACCCATGGCAAATTCCATGGCA-3' (sense) and 5' -TCTAGACGGCAGGTCAGGTCCACC-3' (antisense);

gATG5: 5'-GCGAATTCGATGACAGATGACAAAGATG-3' (sense) and 5'-GCGGATCCTCAATCAGTAGGTCGGGG-3' (antisense);

SOD 1: 5'-ATGGAGATCATGGCTTCCATGTGC-3' (sense) and 5'-CCAGCATTTCCAGTTAGTTTGCTCTC-3' (antisense):

SOD 2: 5'-ACATCAGTGCAGAGATCATGCAGC-3' (sense) and 5'-TGTTGTTCCTTGCAAAGGATCTTG-3' (antisense);

Catalase: 5'-AAGCTGAATATTATGACAGTTGGG-3' (sense) and 5'-ATCCATCAGGAATACCACGATC-3' (antisense):

GPX4: 5'-TTCGTCTGCATCATCACCAACGTG-3' (sense) and 5'-CACCACTTGGCCCTCACGGTTG-3' (antisense)

\subsection{Quantification of mitochondrial membrane potential (TMRE staining)}

For determination of mitochondrial membrane potential, cells were stained with TMRE (Molecular Probes; final concentration $100 \mathrm{nM}$ ) for $30 \mathrm{~min}$ and analyzed by confocal microscopy. The quantification of the membrane potential was performed with the program ImageJ as described above.

\subsection{Oxidative stress resistance and compensatory proliferation}

Cells were treated with one single dose of hydrogen peroxide (30\% stock solution, Calbiochem) in the range from $3.3 \mathrm{mM}$ to $22.8 \mathrm{mM}$ for $10 \mathrm{~min}$ in growth medium. Afterwards the medium was replaced by fresh growth medium. Cells were treated when they had reached 50\% confluency, to allow further proliferation. After $6 \mathrm{~h}$ and $24 \mathrm{~h}$ the remaining adherent cells were detached with trypsin and counted in a Neubauer chamber, resulting in the number of surviving cells. For proliferation assays the supernatant was added $6 \mathrm{~h}$ after hydrogen peroxide treatment to a second set of cells that had been seeded $6 \mathrm{~h}$ before. After $18 \mathrm{~h}$ the total cell number was determined by counting cells in a Neubauer chamber.

\subsection{Statistics}

Results are expressed as means \pm s.e.m. of $n$ experiments, apart from the growth curves where SD was used. ANOVA was used to compare sets of data apart from the determination of telomere length where a two-tailed $t$-test was used. Differences were considered statistically significant when $p<0.05$.

\section{Results}

\subsection{Prolonged life span of PEF}

Embryonic fibroblasts were isolated from $10 \mathrm{~d}$ old pigeon (PEF) respectively chicken embryos (CEF) and cultivated from passage 5 in triplicate till they reached replicative senescence. While CEF ceased proliferation already after $49 \mathrm{PD}$ and $53 \mathrm{~d}$, the proliferative lifetime of PEF was about one-third longer, and PEF were reaching replicative senescence after $80 \mathrm{~d}$ and $61 \mathrm{PD}$ (Fig. 1A). Senescent CEF as well as senescent PEF exhibited a 1.5-2-fold increase in cell size (Fig. 1B), comparable to senescent human fibroblasts or human endothelial cells that were aged in vitro. In correlation with this fact a moderate increase of the F-actin cytoskeleton namely stress fibers was observed (Fig. 1B). Staining of non-proliferating cell populations for the senescence marker SA- $\beta$-galactosidase and comparing them to young cells verified the senescent status. In replicative senescence $68.8 \%$ of the CEF and $74.5 \%$ of the PEF were SA- $\beta$-galactosidase positive (Fig. 1C), while only a few young CEF and PEF (less than $0.1 \%$ ) exhibited SA- $\beta$-galactosidase activity (data not shown).

When the telomere length of young CEF and PEF was determined by Q-FISH and compared to cells, which were two passages away from the postmitotic stage, both old populations demonstrated a significant reduction in the median telomere fluorescence intensity (Fig. 1D). The telomers of old PEF at this time point were actually shorter than those of CEF, however this difference was not significant. As telomere shortening is important for the process of senescence induction, we investigated if the reduced life span of CEF was caused by enhanced rates of telomere shortening. Indeed, PEF exhibited a significantly decreased loss of telomeric sequences per passage compared to CEF; the shortening rate was roughly $66 \%$ of that of $C E F$ (Fig. $1 E$ ). This may explain the longer life span of PEF and why they reach senescence with shorter telomeres than $\mathrm{CEF}$.

Interestingly, the postmitotic phase of CEF and PEF lasted only up to four weeks, while in human endothelial cells we observed a much longer senescent phase (Jendrach et al., 2008). During this time an increasing number of CEF and PEF exhibited a distinct apoptotic morphology compared to the cells at the beginning of replicative senescence. The morphological parameter was correlating with the loss of cells and the appearance of a growing amount of cell debris in the medium. This observation indicates a relatively short postmitotic stage, followed by an efficient removal of old avian cells by apoptosis.

\subsection{No age-related increase of ROS in old PEF and CEF}

According to the free radical hypothesis of aging, the ROS levels should be higher in CEF compared to PEF. To test this hypothesis, the ROS levels of young and senescent CEF and PEF were compared by DHE staining. Young CEF and PEF exhibited similar ROS values (Fig. 2A) and equal resistance to oxidative stress (Fig. S1). In contrast, the ROS content of a human cell line (HeLa) was more than 2.5-fold elevated in comparison to the avian cells. Aging of PEF did not alter their ROS content significantly (Fig. 2A). Surprisingly, senescent CEF exhibited even lower ROS levels when compared to young $\mathrm{CEF}$, as revealed by quantification of the relative ethidium fluorescence in microscopical images (Fig. 2A) and by FACS as a second method to exclude a methodical error (Fig. S2). As additional controls, young CEF were treated with the glutathione precursor $\mathrm{N}$-acetylcysteine (NAC), which increases levels of the ROS scavanger glutathione. After preincubation with NAC the ROS content was significantly reduced in young CEF, resembling the ROS levels measured in old CEF (Fig. 2A). In the reverse experiment, old CEF were treated with buthionine sulfoximine (BSO), which inhibits the glutathione synthesis. Here, reduction of glutathione resulted in a ROS increase (Fig. 2A), thus demonstrating the reliability of the ROS measurements.

Furthermore, staining of young and senescent CEF with dihydrorhodamine 123 , another well-established ROS indicator, confirmed the significant lower ROS content in senescent CEF (Fig. 2B). The reduced ROS production in senescent CEF was not related to changes in basic respiration or uncoupling as revealed by the measurement of oxygen consumption in young and old CEF (Fig. S3). Taken together, these data confirm the lower ROS levels in avian cells and indicate that in contrast to several reports on mammalian cells, ROS levels were not increased in senescent avian cells.

\subsection{Senescent avian cells exhibit no oxidatively damaged proteins or $m t D N A$}

The ROS measurements by fluorescent dyes visualized only the ROS levels in the final stage of the life of CEF and PEF. Thus, although no increased oxidative stress was observed with age, ROS-induced damage accumulating during the whole life span could contribute to the aging of avian cells and explain the shorter life span of CEF. Therefore, the amount of carbonylated proteins was determined by oxyblotting. Whole cells lysates of young and senescent CEF and PEF were separated by gel electrophoresis and the carbonylated proteins were detected 
by antibody staining and normalized to the total protein content (Fig. 3A). In accordance with the values obtained from the ROS measurements, young CEF and PEF exhibited similar amounts of oxidized proteins. In senescent avian cells no increase in the amount of oxidized proteins was observed, in fact old cells contained even a reduced amount of carbonylated proteins
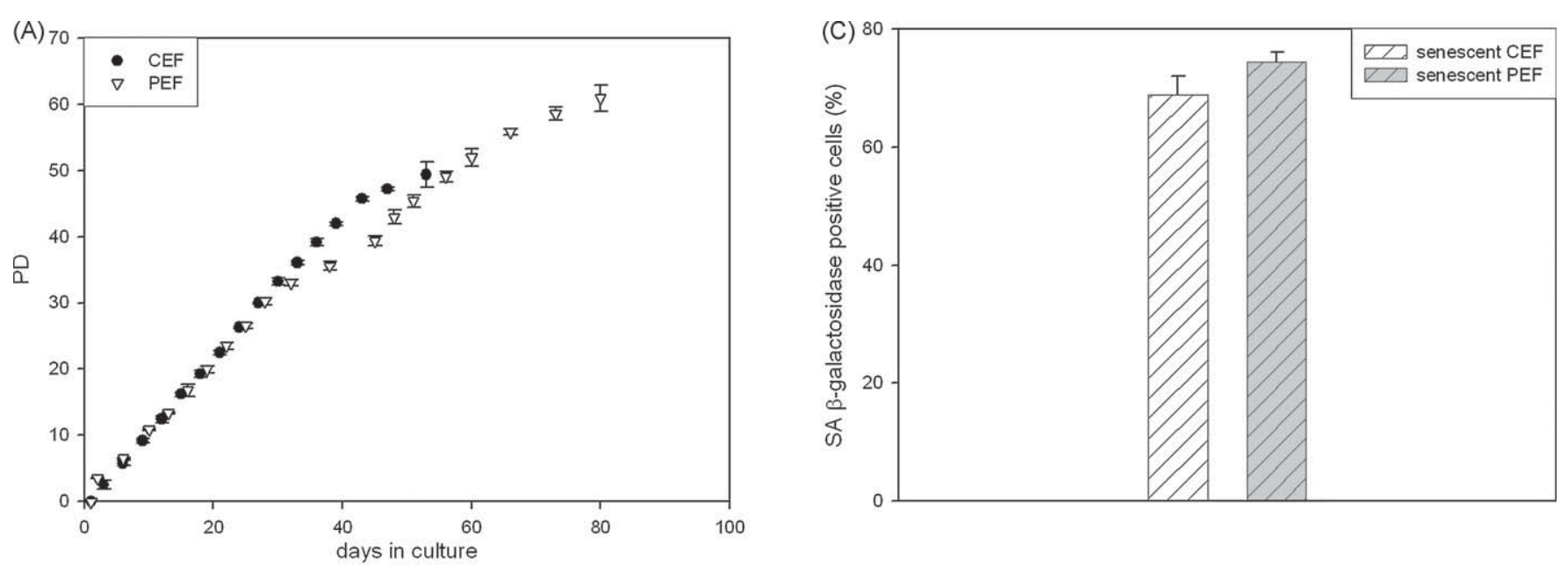

compared to young ones, irrespective of the MLSP of the donor species.

To confirm the apparent absence of ROS-induced damage in old avian cells, the integrity of the mtDNA was determined by semiquantitative PCR. This method for detection of deletions in the mtDNA could only be applied to CEF as the sequence of the PEF
(B)

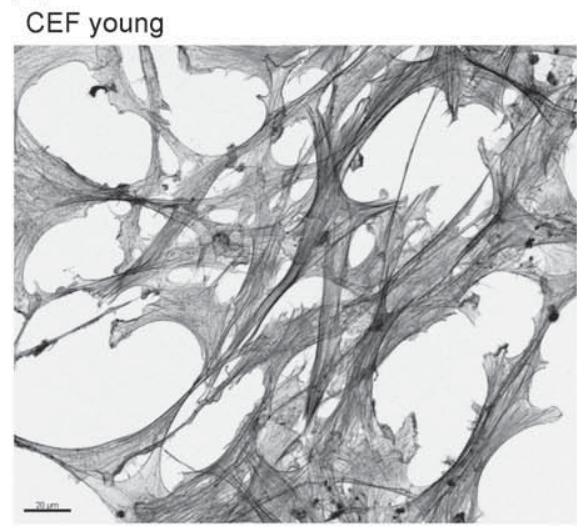

PEF young

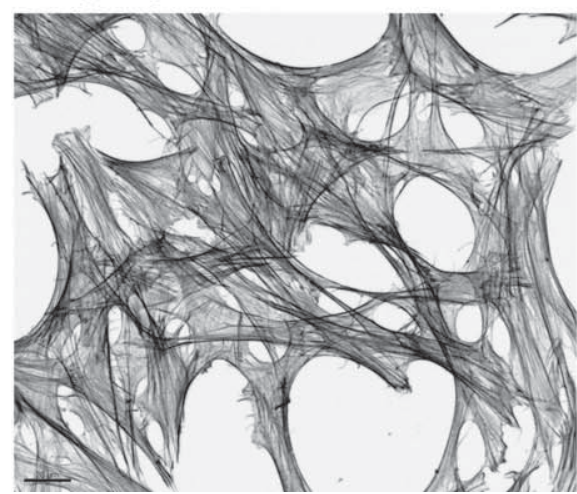

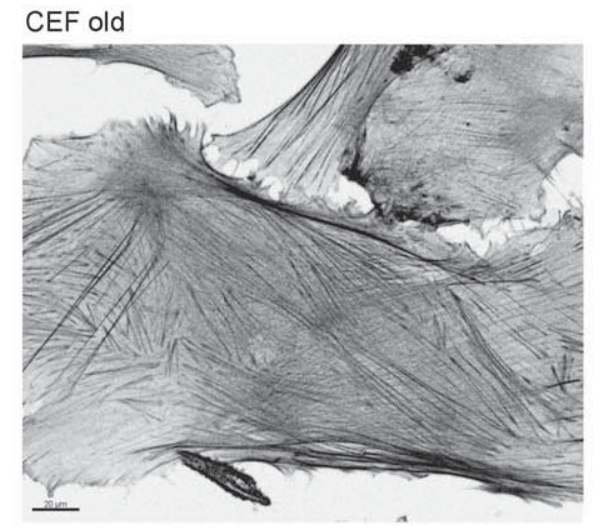

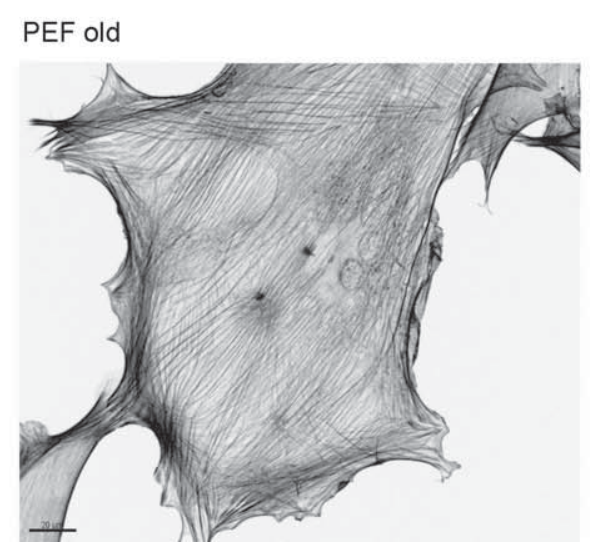

Fig. 1. Extended replicative lifespan of PEF.

(A) Young CEF and PEF (passage 5) were cultivated in triplicates till they reached replicative senescence. The growth curve of CEF exhibits a reduced life span compared to PEF.

(B) LSM images of young (A), senescent CEF (B), young (C) and senescent PEF (D) after staining of the F-actin skeleton with TRITC-phalloidin. An age-related increase in cell size

is apparent as well as a moderate increase in stress fibers; bar $=20 \mu \mathrm{m}$.

(C) Young CEF and PEF and cells in replicative senescence were stained for the senescence marker SA- $\beta$-galactosidase. While less than 0.1 of the young cells expressed SA- $\beta$ galactosidase (data not shown), the majority of the postmitotic CEF and PEF were positive for SA- $\beta$-galactosidase, indicating that most cells of these populations were senescent; at least 200 cells/experiment; $n=3$.

(D) The relative median telomere fluorescence intensity was analyzed by Q-FISH in young and old CEF and PEF, whereas the old cells were two passages from reaching replicative senescence. Both cell types demonstrated a significant reduction of telomere fluorescence during aging; $n=3 ;$ CEF: $p<0.01 ;$ PEF: $p<0.005$.

(E) Based on the experiment shown in D, the loss of telomeric sequences per passage was determined in the two avian cell types; PEF exhibited a significantly slower shortening rate than CEF; $n=3 ; p<0.05$. 

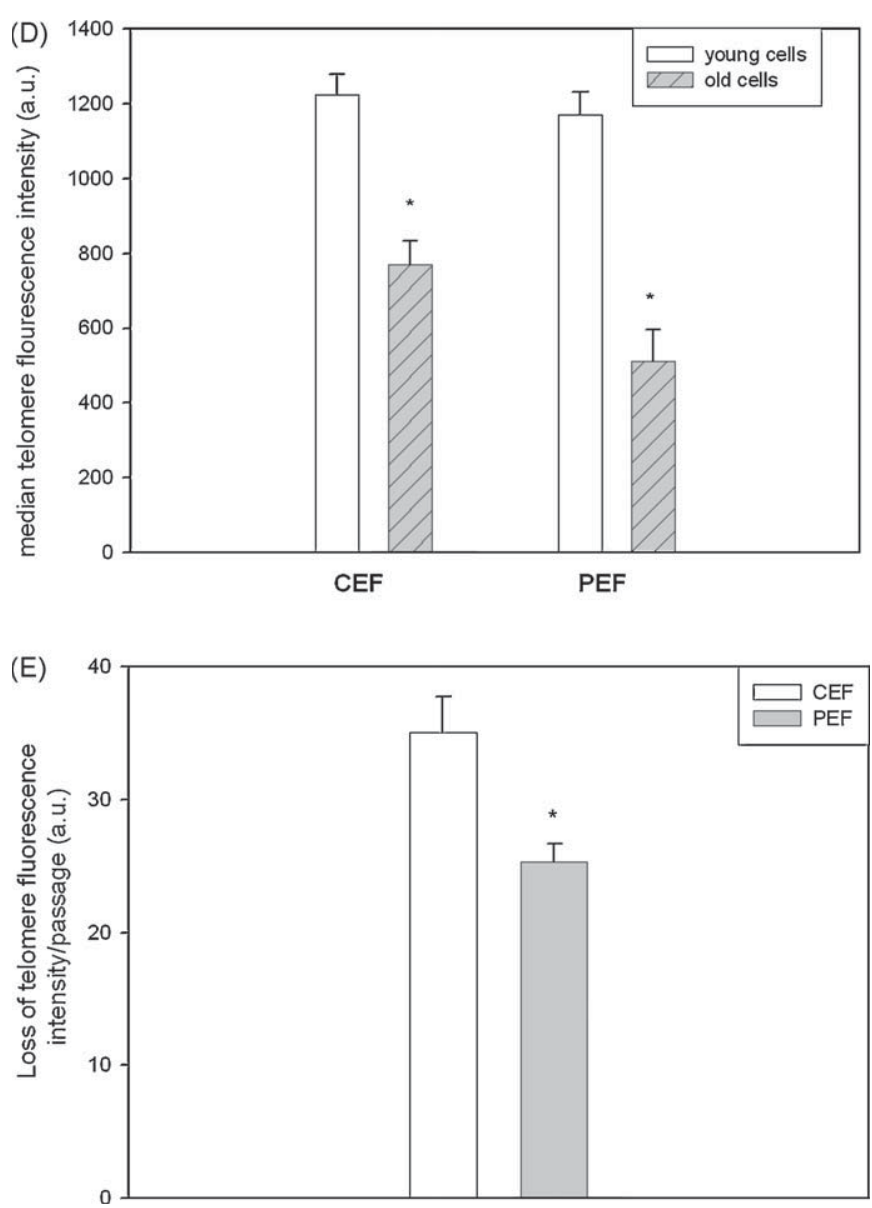

Fig. 1. (Continued).

mtDNA is not known and the primers for the CEF mtDNA did not yield any bands in the PCR reaction. The relative amplification product, which covers about half of the chicken mtDNA genome, was similar in young and senescent CEF (Fig. 3B). For visualization of the mtDNA status on the single cell level in vivo, young and old CEF were stained with the DNA-intercalating dye Picogreen, as the Picogreen fluorescence intensity correlates positively with the amount of DNA. Young CEF contained quite large nucleoids, which were situated preferentially at the tips of the mitochondria (Fig. 3C a and magnification in c). No changes in the amount of nucleoids or fluorescence intensity of the stained nucleoids were detectable when comparing young to senescent CEF (Fig. $3 \mathrm{C} \mathrm{b}$ and magnification in d), confirming the absence of age-related mtDNA damage observed in the PCR reactions.

The stable ROS levels and the lack of ROS-induced damage in aged cells most probably contribute to the high MLSP of birds. An enhanced expression of scavenging enzymes is able to lower ROS levels and counteract ROS-induced damage (Orr and Sohal, 1994; Mysore et al., 2005; Rezvani et al., 2006). Therefore, the expression levels of the scavenging enzymes SOD 1, SOD 2, catalase and GPX4 were determined in young and old CEF by semi-quantitative RTPCR, but no significant age-related changes occurred (Table 1 ). This experiment was not performed with PEF as the sequence of the respective pigeon enzymes is not known.

\subsection{No changes of the lysosomal compartment during aging of avian cells}

The autophagosomal/lysosomal pathway acts as QC mechanism for the maintenance of mitochondrial and cellular functionality
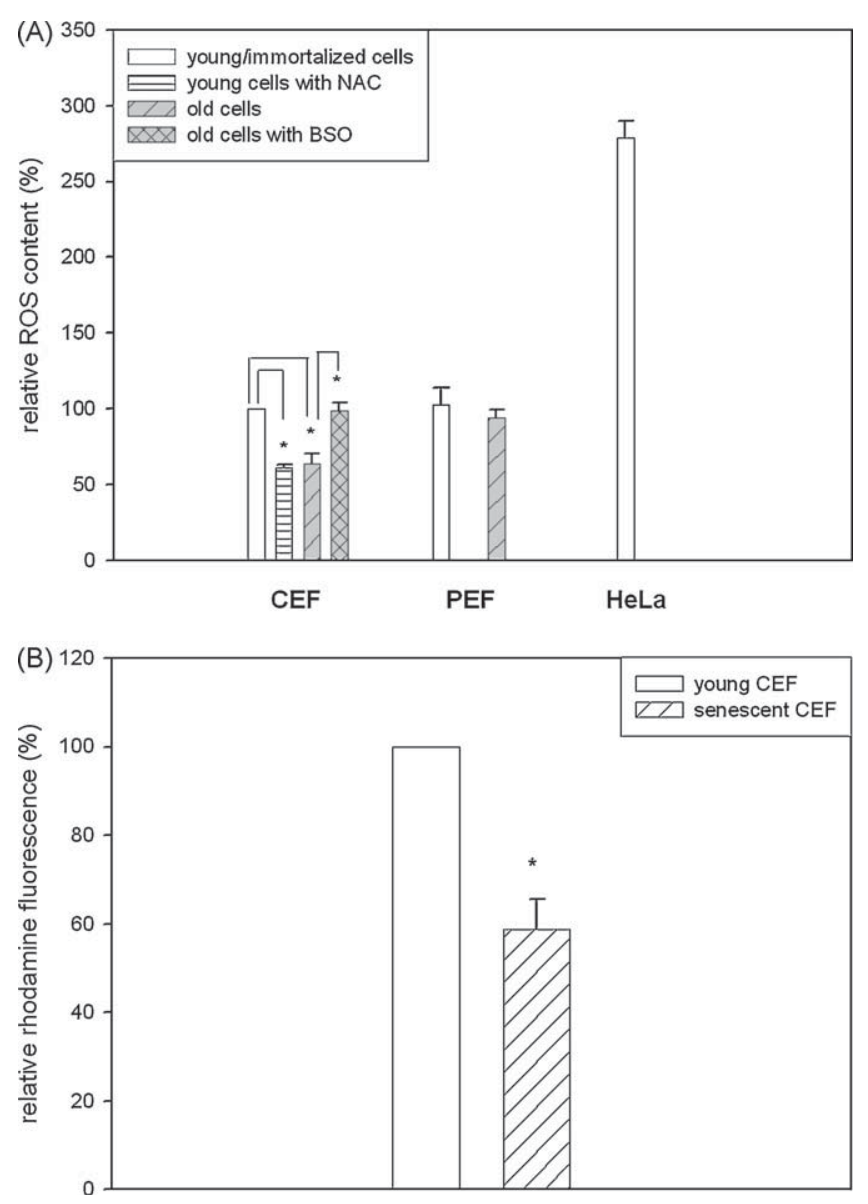

Fig. 2. No increase of ROS in senescent avian cells.

(A) Young and old CEF and PEF were stained with DHE and the relative ethidium fluorescence was determined (for details see Section 2); the relative fluorescence intensity of young CEF was set as $100 \%$. While young and senescent PEF showed similar ROS levels (young PEF: $n=7$, old PEF: $n=3$; at least 8 fields of view/ experiment), senescent CEF exhibited a significant decrease of the ethidium fluorescence, indicating a reduced ROS content in senescent CEF (young CEF: $n=8$, senescent CEF: $n=5 ; p<0.005$; at least 8 fields of view/experiment). Addition of NAC to young CEF decreased ROS levels significantly, while addition of BSO to old cells increased the ROS content; young CEF + NAC: $n=3, p<0.05$; old CEF + BSO: $n=5, p<0.0005$; at least 8 fields of view/experiment).

(B) Young and old CEF were stained with DHR and the relative rhodamine fluorescence was determined; the relative fluorescence of young CEF was set as $100 \%$. Comparable to the ROS detection by oxidation of DHE also here senescent CEF exhibited significantly reduced ROS levels; $n=3$; at least 100 cells/experiment; $p<0.05$.

(Tatsuta and Langer, 2008). Old mammalian cells are characterized by a large increase of the lysosomal population, a process, which probably balances the age-induced downregulation of autophagosomal and lysosomal enzymes in these cells (Kiffin et al., 2006). Increased autophagy can expand the life span (Simonsen et al., 2008) and therefore stable autophagsomal and lysosomal capacities throughout the life could contribute to the "healthy aging" of avian cells. To assess this hypothesis, young and senescent avian cells were stained with the dye Lysotracker Green, which accumulates in lysosomes. Young as well as old CEF and PEF contained a huge amount of lysosomes, filling most of the intracellular space (Fig. 4A). For quantification of the apparent equal lysosome population in young and old cells, the activity of the lysosomal enzyme acid phosphatase was determined (Fig. 4B). Young and old CEF exhibited a very similar acid phosphatase activity, thus supporting the microscopical images in Fig. 4A. Furthermore, the mRNA expression of ATG5, a key gene of the autophagosomal pathway, was analyzed by RT-PCR in young and 
(A)

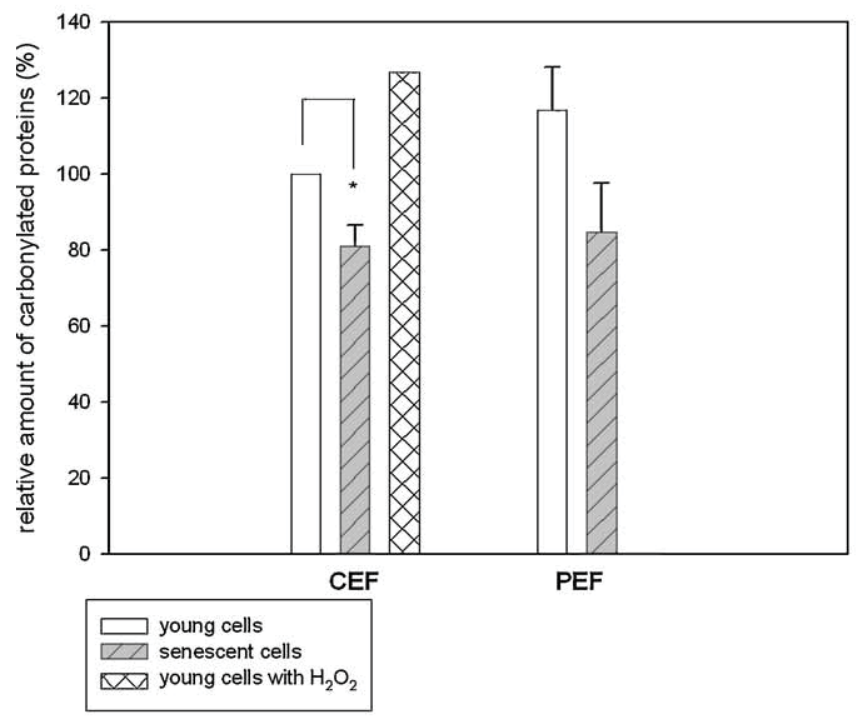

(C)
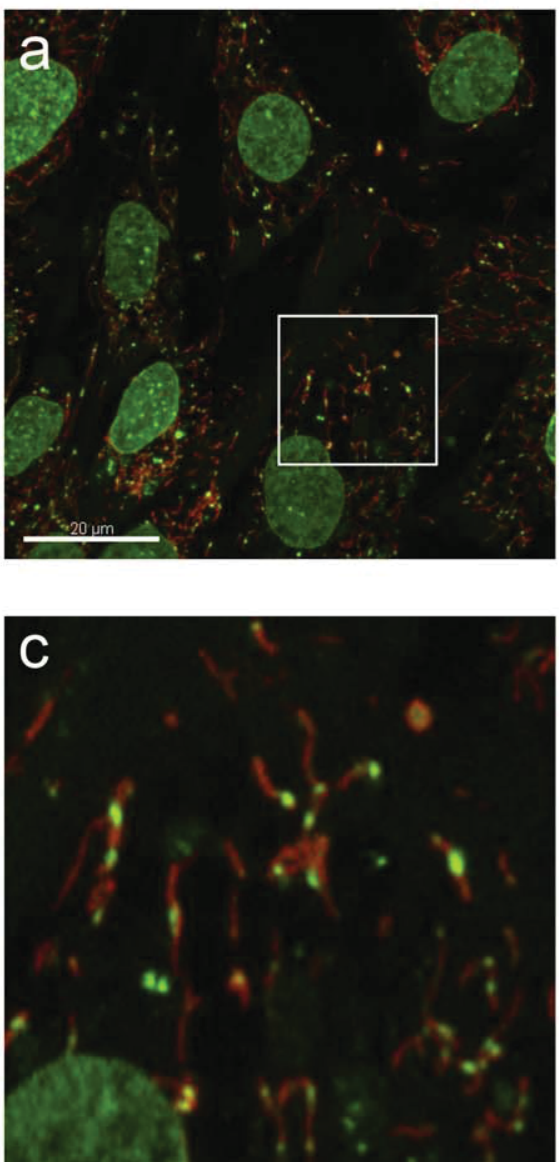

(B)
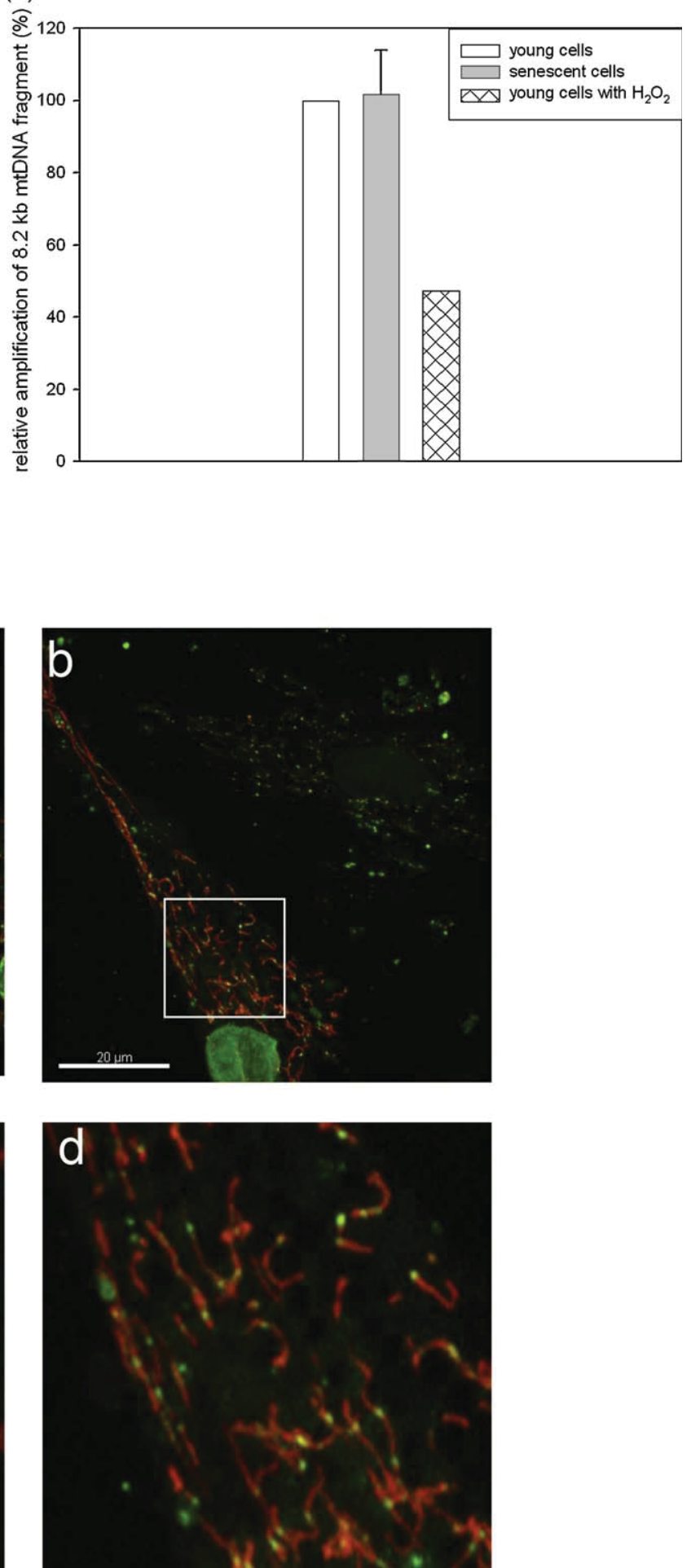

Fig. 3. No ROS-induced damage in senescent avian cells.

(A) The oxidative modification of cellular proteins in young and senescent CEF and PEF was determined by OxyBlot. For the quantification the relative amount of oxidized proteins in young CEF was set as $100 \%$. As control young CEF were treated for $1 \mathrm{~h}$ with $16.3 \mathrm{mM}$ hydrogen peroxide. While the hydrogen peroxide treatment increased the amount of carbonylated proteins, senescent CEF as well as senescent PEF demonstrated a decrease of carbonylated proteins compared to the respective young cells; $n=4$, $p<0.05$.

(B) The integrity of the mtDNA of young and senescent CEF was compared by semi-quantitative PCR; the relative amplification product of young CEF was set to $100 \%$. As control young CEF were treated for $3 \mathrm{~h}$ with $9.8 \mathrm{mM}$ hydrogen peroxide. While addition of hydrogen peroxide clearly reduced the relative amplification of the $8.2 \mathrm{~kb}$ mtDNA fragment indicating mtDNA damage, no difference in the relative amplification product of young and old CEF was visible, indicating a lack of mtDNA damage in senescent CEF; $n=5$.

(C) Young (a and magnification in c) and senescent (b and magnification in d) CEF were double stained with Mitotracker Deepred (red) to confirm the mitochondrial localization and with Picogreen to visualize the mtDNA (green). The Picogreen fluorescence intensity correlates positively with the amount of DNA. The fluorescence intensity and the number of the nucleoids are comparable in young and old cells, confirming the absence of mtDNA damage in senescence; bar $=20 \mu \mathrm{m}$. 
Table 1

Relative mRNA expression of scavenging enzymes in young and old CEF.

\begin{tabular}{lrrrr}
\hline & \multicolumn{1}{c}{ SOD 1 } & \multicolumn{1}{c}{ SOD 2 } & \multicolumn{1}{c}{ Catalase } & \multicolumn{1}{c}{ GPX4 } \\
\hline Young CEF & $1 \pm 0.14$ & $1 \pm 0.07$ & $1 \pm 0.01$ & $1 \pm 0.08$ \\
Old CEF & $1.67 \pm 0.31$ & $1.34 \pm 0.31$ & $0.91 \pm 0.2$ & $1.11 \pm 0.14$ \\
\hline
\end{tabular}

RNA was isolated from young and old CEF and RT-PCR was performed for the scavenging enzymes superoxide dismuatase 1 and 2 (SOD), catalase and glutathione peroxidase 4 (GPX4). The expression levels of the respective enzymes in young cells was set as $1 ; n=3$ for young and old cells.

old CEF. ATG5 is a $33 \mathrm{kDa}$ protein, which forms a complex with ATG12 and ATG16L at the membrane of the phagophore (the evolving autophagosome). In accordance with the data presented above, the gATG5 transcript levels were only slightly and not significantly decreased in old CEF (Fig. 4C).
3.5. Autophagy and compensatory proliferation act as QC mechanisms in proliferating avian cells

The stable autophagsomal and lysosomal capacities in avian cells imply that autophagy could act here as a QC. To test this hypothesis, gATG5 was amplified from chicken cDNA, tagged with GFP and cloned into an avian viral vector, while GFP transfected cells were used as control. Stable GFP overexpressing cells showed mainly a cytoplasmatic fluorescence (Fig. 5A), while GFP-ATG5 transfected cells exhibited as expected in addition to the cytoplasmatic fluorescence strongly fluorescent spots, which are most probably autophagosomes (Fig. 5B). Western blotting with an anti-GFP antibody confirmed the recombinant expression of the full-length proteins (data not shown). To determine the influence of ATG5 overexpression on the autophagosmal pathway, the

(A)
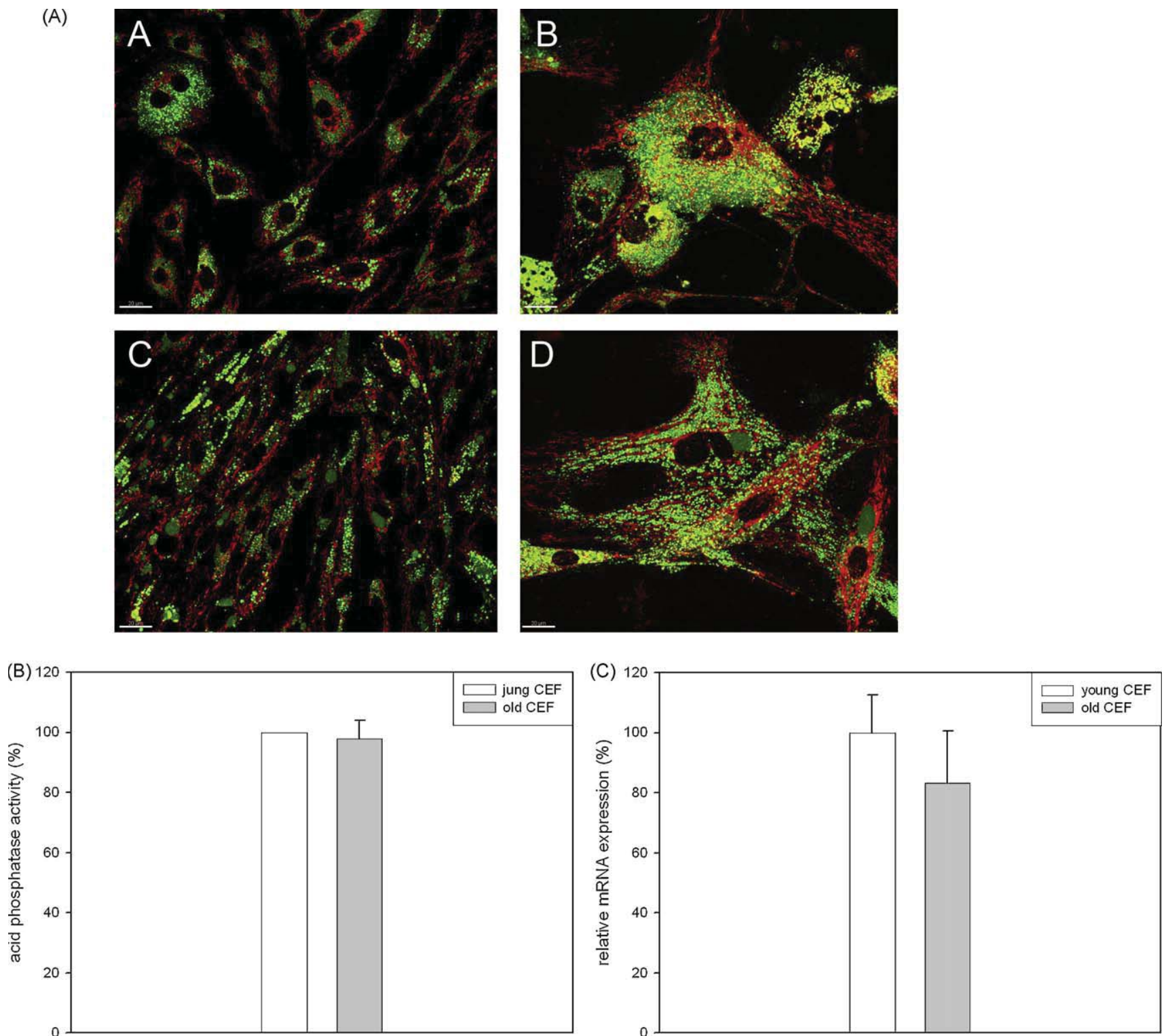

Fig. 4. No changes of the lysosomal compartment during aging of avian cells.

(A) Young (A), senescent CEF (B), young (C) and senescent PEF (D) were stained with the dye Lysotraker Green to visualize the lysosomes (green). Furthermore cells were costained with the mitochondrial membrane potential indicator TMRE for visualization of the mitochondria (red). Both young and senescent CEF and PEF exhibit a large number of lysosomes. A moderate elongation of mitochondria in senescent cells is also discernable; bar $=20 \mu \mathrm{m}$.

(B) The acid phosphatase activity was quantified in young and old CEF. The acid phosphatase activity of young CEF was set as $100 \%$. In agreement with the data presented in $\mathrm{A}$ no differences of the lysosomal activity became apparent during age; $n=6$.

(C) RT-PCR for the gATG5 transcript levels was performed with RNA from young and old CEF and normalized on beta-actin mRNA. The ATG5 expression level of young CEF was set as $100 \%$. The ATG5 mRNA expression was similar in young and old cells; young CEF: $n=4$, old CEF: $n=3$. 
activity of the acid phosphatase was quantified. Young ATG5 overexpressing cells exhibited a higher level of acid phosphatase activity compared to GFP transfected cells, indicating that overexpression of ATG5 increased indeed autophagy (Fig. 5C).

The growth curves of GFP and ATG5 overexpressing CEF revealed that ATG5 transfected cells proliferated considerably longer, reaching 47 PD compared to GFP expressing cells, which went already after 40 PD into replicative senescence (Fig. 5D). Interestingly, and in agreement with the data presented above, overexpression of ATG5 did not alter the ROS levels in young or old avian cells (Fig. 5E) The decrease of ROS, which we observed in untransfected cells (Fig. 2) was not observed in the tranfected senescent cells, an effect most probably caused by increased stress due to the continued presence of the virus and which could explain the slightly shorter life spans of transfected versus non-transfected CEF.

As ROS content was not the reason behind the life span prolonging effect of ATG5 overexpression, additional parameters were investigated. The mitochondrial membrane potential of young and old CEF was quantified by staining cells with the membrane potential sensitive dye TMRE. Young ATG5 overexpressing cells had a significantly higher membrane potential compared to GFP expressing cells, while in old cells the membrane potential was evenly decreased (Fig. 5F). Furthermore, proliferating stable GFP and gATG5 transfected cells were treated for $10 \mathrm{~min}$ with different doses of hydrogen peroxide and the number of surviving cells was determined after $6 \mathrm{~h}$ and $24 \mathrm{~h}$. In both cell types short-term addition of hydrogen peroxide caused a dose-dependent reduction of the cell number and a transient growth arrest of the surviving cells (Fig. 5G). However, overexpression of gATG5 conferred an elevated resistance against oxidative stress-induced apoptosis compared to GFP transfeced cells. Taken together, overexpression of ATG5 enhanced mitochondrial fitness and reduced apoptosis resulting in an expanded live span, thus indicating a role for autophagy in the aging process of avian cells.

The survival of cells after oxidative stress can be also enhanced by a process called apoptosis-induced compensatory proliferation, where apoptotic cells trigger the proliferation of the surrounding cells, as long as these are not postmitotic (Fan and Bergmann, 2008). To determine if this mechanism applies also to avian cells, a first set of young CEF and PEF was treated for $10 \mathrm{~min}$ with hydrogen peroxide to induce apoptosis. After $6 \mathrm{~h}$ the supernatant was applied to a second set of young CEF or PEF, respectively. After $18 \mathrm{~h}$ of incubation in this conditioned medium the total number of adherent cells was increased with both cell types. The increase of cell number correlated positively with the dose of hydrogen peroxide that had been applied to the first set of cells (Fig. 6). Application of the supernatant to an empty cell culture dish did not yield any cells after $18 \mathrm{~h}$, demonstrating that indeed compensatory proliferation occurred after oxidative stress-induced apoptosis, which thus acts QC mechanism in proliferating avian cells.

\section{Discussion}

As ROS is considered as one of the main factors influencing aging of mammalian cells (Lu and Finkel, 2008; Percy et al., 2009), we investigated here the impact of ROS on the aging process of fibroblasts derived from birds with significant different in vivo life spans. While chicken have - depending on the race - a MLSP of 5-8 years, pigeons are very long-lived with a MLSP up to 35 years. In vitro aging of embryonic fibroblasts obtained from chicken and pigeon embryos indeed revealed that PEF had a longer life span and underwent more population doublings before they reached senescence, but the difference was clearly smaller than the difference in the MLSP of the donor species.

The telomere length decreased with increased proliferation time as in mammalian cell models, thus suggesting a similar influence on the life span of avian cells. Despite the difference in life span of CEF and PEF both exhibited a similar telomere length in age. However, PEF lost significantly less telomeric sequences per passage than CEF. This could explain, why PEF manage to proliferate with shorter telomeres than CEF, thus entering senescence later than CEF. As the shortening is milder, PEF may have more time to develop adaptive mechanisms to compensate for telomere length decrease and therefore end up with shorter telomeres compared to CEF. But it could be also that the "inherited" telomere length of PEF at which senescence is triggered is different from that of CEF. Another possibility could be an enhanced protection mechanism for shielding of telomere ends in PEF that would allow PEF to stay in the replicative phase while CEF with the same telomere length had already entered the replicative senescence.

Avian cells exhibited a much lower ROS load compared to the human cell line HeLa, confirming the low ROS production in birds as shown before (Ku and Sohal, 1993; Barja et al., 1994). While young CEF and PEF exhibited similar ROS levels, we hypothesized that the shorter life span of CEF could be caused by increased oxidative stress during aging. However, CEF contained at the end of their replicative life span even less ROS than young CEF, while the ROS levels of young and senescent PEF remained similar. The agedepending decline of ROS levels in CEF was confirmed by different methods and could not be related to changes in the oxygen consumption or the respiratory coupling state. This fits to the hypothesis that ROS production under various different conditions does not depend on the respiratory activity (Barja, 2007). In virusinfected CEF however, the ROS levels remained stable during the whole live span, indicating that the age-induced ROS decline of CEF can be affected by stress. Interestingly, Sasaki et al. (2008) measured a 1.8-fold increase of superoxide in brain of 10 -year-old pigeons in comparison to 2-year-old pigeons, while we saw no increase of ROS in senescent PEF. The different cell types or the fact that 10-year-old pigeons are still not at the end of their life span could explain this discrepancy; it would be interesting to investigate the ROS levels in different tissues of pigeons at the end of their life span. However, the age-related ROS increase measured by Sasaki et al. (2008) was significantly lower in pigeons than in mice, thus these in vivo data agree with our in vitro data on the lack of a strong ROS increase in birds. Thus, the stable ROS content in senescent avian cells differs from the elevated ROS levels observed in many senescent mammalian cells and tissues (Ali et al., 2006; Unterluggauer et al., 2007; Chabi et al., 2008). This feature seems to be conserved at least on the single cells level independent of the MLSP of the birds, indicating that stabilization of ROS levels throughout the live span is a common and conserved trait in avian cells.

Correlating with the absence of increased ROS in senescence was a lack of accumulated ROS-induced damage in old PEF and CEF. No increase in the carbonylation state of the proteins occurred in senescent avian cells, in contrast old cells even showed a reduction of oxidized proteins. This is in accordance with the unaltered integrity of the mtDNA in senescent CEF. In contrast, prior work from our lab demonstrated that senescent primary human endothelial cells contained an elevated amount of oxidized proteins as well as seriously damaged mtDNA (Jendrach et al., 2005; Unterluggauer et al., 2007). Also many other authors have detected increased oxidative damage of proteins and mtDNA in senescent mammalian cells and tissues (Chaudhuri et al., 2006; Passos et al., 2007; Senthil et al., 2008; Stolzing et al., 2008; Hayashi et al., 2008). Taken together, the absence of ROS-induced 

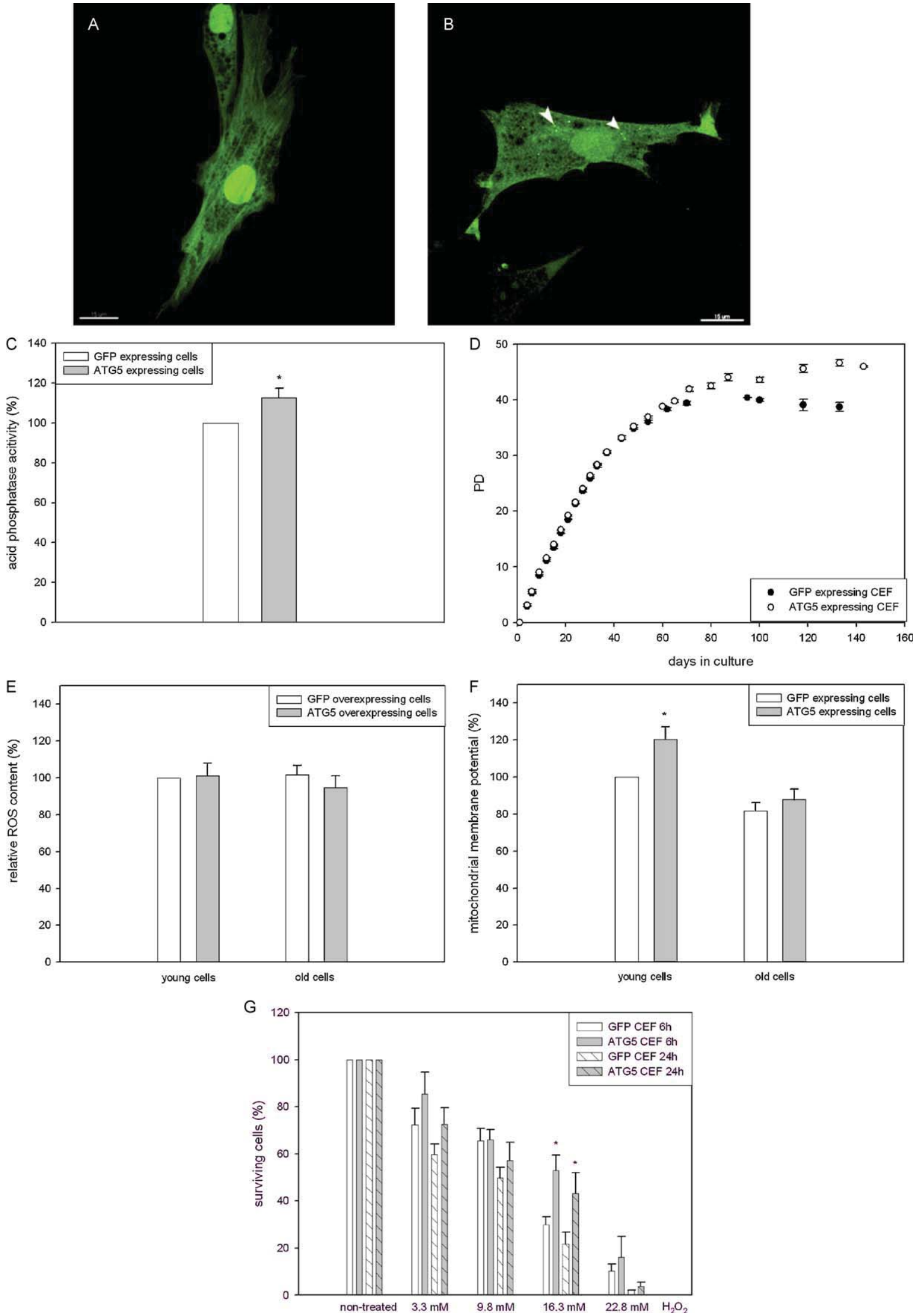

Fig. 5. Autophagy acts as QC mechanism in avian cells.

Stable transfected GFP CEF (A) exhibited mainly cytoplasmatic fluorescence, while GFP-gATG5 overexpressing CEF (B) showed the typical fluorescent autophagosomes (arrowheads) in addition to a cytoplasmatic fluorescence; bar $=15 \mu \mathrm{m}$.

(C) The lysosomal activity of young gATG5 and GFP overexpressing CEF was quantified by determining the acid phosphatase activity. The acid phosphatase activity of GFP expressing CEF was set as 100\%. Increased ATG5 expression resulted in a significant increase of acid phosphatase activity, indicating elevated autophagy levels in these cells; $n=3 ; p<0.05$. 


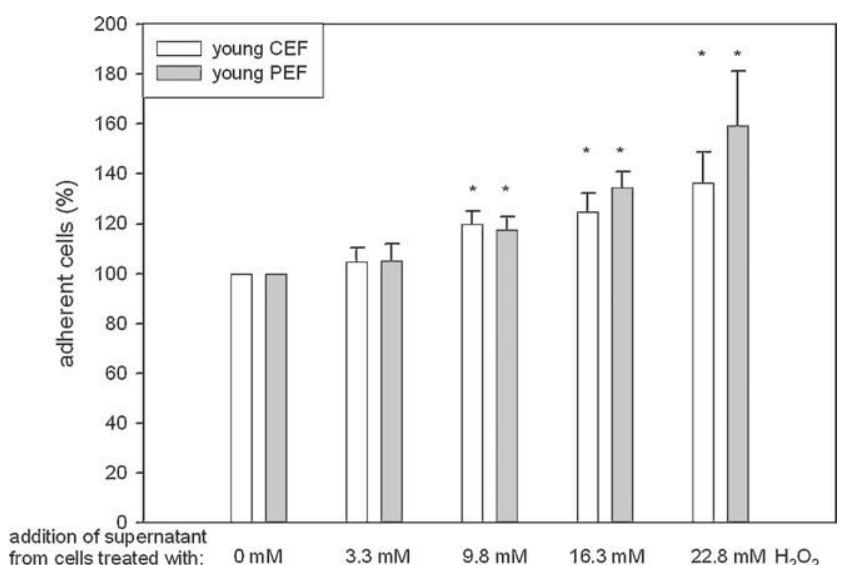

Fig. 6. Apoptosis-induced compensatory proliferation in avian cells after oxidative stress.

A first set of young CEF and PEF were treated for $10 \mathrm{~min}$ with the indicated doses of hydrogen peroxide to induce apoptosis. $6 \mathrm{~h}$ later the supernatant was applied to a second set of young CEF or PEF, respectively, and the total cell number was determined $18 \mathrm{~h}$ later. The number of cells that obtained supernatant from nontreated cells ( $0 \mathrm{mM}$ hydrogen peroxide) was set as $100 \%$. CEF as well as PEF demonstrate an increase of their cell number, which was dependent on the dose of hydrogen peroxide that had been applied to the first set of cells, indicating that a dose-dependent apoptosis-induced compensatory proliferation occurred in avian cell populations after hydrogen peroxide treatment; $n=5$ (CEF), $n=4$ (PEF), $p<0.05$.

damage in senescence was, like the lack of ROS increase, a common characteristic of avian cells, independent of the MLSP of the donor species.

The equal resistance against ROS-induced damage of PEF and CEF was further confirmed by subjecting young cells of both cell types to a transient boost of oxidative stress, where the percentage of surviving PEF and CEF was similar. These results differ form data obtained by Ogburn et al. (2001), which indicate a higher resistance of avian embryonic fibroblasts from a long-lived species (budgerigar) to oxidative stress than fibroblasts derived from a short-lived species (Japanese quail). This discrepancy could be either species-specific or be caused by the different methodical setup (transient boost of hydrogen peroxide versus permanent exposition). However, a similar resistance of PEF and CEF against oxidative stress is consistent with our results. Thus, while metabolic differences between pigeons and chicken (good flyer versus non-flyer) certainly may influence ROS levels, the antioxidant defense and the MLSP of the respective species in vivo (Cohen et al., 2008), our data indicate that ROS and ROS-induced damage are of minor or no importance at least for the in vitro aging of avian fibroblasts.

To determine the mechanisms, which are responsible for the lack of ROS increase in aging avian cells, different putative methods were investigated. As increased expression of SOD and catalase reduces ROS and ROS-induced damage in different systems (Orr and Sohal, 1994; Mysore et al., 2005; Rezvani et al., 2006), we compared the transcription levels of SOD 1 and 2, catalase and GPX4 in young and old CEF. Although the expression levels of SOD 1 were slightly elevated in old cells, no significant differences were observed.

The presence of a large population of lysosomes throughout the life span of CEF and PEF and the stable activity of the lysosomal enzyme acid phosphatase were remarkable, because this contrasts from the age-related increase of the lysosomal compartment in mammalian cells; for example, young endothelial cells (HUVEC) contained only a few lysosomes while in old HUVEC a large lysosomal population was present (M. Voeth, unpublished data). In mammalian cells this is probably a compensatory mechanism to counteract the downregulation of autophagosomal and lysosomal enzymes in age (Kiffin et al., 2006; Mai, unpublished data). A high and stable amount of lysosomes throughout life indicates that autophagy could be an important pathway in avian cells. Indeed, ATG5 overexpression improved mitochondrial fitness as revealed by the elevated membrane potential and prolonged life span, while it had no influence of the ROS content. These data are consistent with our hypothesis that autophagy acts in avian cells as a mitochondrial QC mechanism and that ROS does not (or only slightly) influence the aging process. Furthermore, increased expression of ATG5 endowed enhanced resistance against oxidative stress-induced apoptosis. This correlates with recent results from Cheng et al. (2009) and Ko et al. (2009), where inhibition of the autophagy protein LC3/ATG8 increased the sensitivity against apoptosis. Thus, we propose that in avian cells the live span extension after ATG5 overexpression is mediated by enhanced mitochondrial fitness and decreased apoptosis rates. Further work should elucidate the molecular mechanisms of this process and its significance in the aging process of birds.

The live span prolonging effect of ATG5 overexpression is particularly interesting, as the increased expression of autophagy genes has yielded different results in the past. While overexpression of Atg8 in Drosophila melanogaster increased the life span of the fly (Simonsen et al., 2008), overexpression of an ATG1 homologue (ULK 3 ) resulted in premature senescence, indicating accordingly a role of this autophagy gene in the mediation of senescence (Young et al., 2009). As ATG8 declines with age while ULK3 is upregulated in senescence, there seem to exist different roles for autophagy proteins in the aging process; some of these proteins appear to have a pro-aging effect, while others prolong live span. ATG5 in avian cells was slightly downregulted during aging and the upregulation by recombinant overexpression expanded the life span, thus ATG5 should be placed like ATG8 in the category of autophagy proteins with an ant-aging effect.

If a cell is too severely damaged, it is removed by apoptosis. In parallel, apoptosis triggers compensatory proliferation of healthy cells. Such a compensatory mechanism has been observed before in D. melanogaster and in different mouse models after induction of apoptosis (Milán et al., 1997; Valentin-Vega et al., 2008), which we can now expand to avian cells. In young, proliferating avian populations damaged cells are removed by apoptosis and at the

(D) Stable overexpressing GFP and GFP-gATG5 CEF were cultivated from passage 7 in triplicates till they reached replicative senescence; gATG5 CEF exhibit an extended life span compared to GFP-expressing cells.

(E) Young and old GFP and GFP-gATG5 tranfected CEF were stained with DHE and the relative ethidium fluorescence was determined; the relative fluorescence intensity of young GFP expressing CEF was set as $100 \%$. Young and old tranfected cells demonstrated no alterations of ROS levels; young cells: $n=8$, senescent cells: $n=7$; at least 8 fields of view/experiment.

(F) The mitochondrial membrane potential of young and old GFP and gATG overxpressing CEF was determined with the membrane potential sensitive dye TMRE. The quantification of the micrographs was performed with the program ImageJ and the membrane potential of young GFP expressing cells was set as $100 \%$. Overexpression of ATG5 resulted in young cells in a significantly upregulated membrane potential compared to the GFP expressing cells, indicating an increased mitochondrial fitness; young cells: $n=5$, senescent cells: $n=10$; at least 8 fields of view/experiment; $p<0.05$.

(G)Stable transfected GFP and gATG5 CEF were either non-treated or treated with the indicted concentrations of hydrogen peroxide. The number of surviving cells was determined 6 and $24 \mathrm{~h}$ after hydrogen peroxide treatment and the number of non-treated cells was set as $100 \%$. Treatment with hydrogen peroxide resulted in a dose-dependent cell loss and a transient growth arrest, but overexpression of GFP-gATG5 rendered cells more resistant compared to GFP expressing cells treated with the same dose of hydrogen peroxide; 6 h: $n=3, p<0.05 ; 24 \mathrm{~h}: n=7, p<0.05$. (For interpretation of the references to color in this figure legend, the reader is referred to the web version of the article.) 
same time proliferation of healthy cells is stimulated; both these processes together counteract the accumulation of ROS-induced damage. In senescent cells the QC mechanism of apoptosis seems to be predominant, perhaps partly due the inability of postmitotic cells to undergo compensatory proliferation.

Taken together, the impact of ROS on in vitro aging of fibroblasts derived from a long-lived and a short-lived avian species was compared for the first time. Senescent cells from both species neither showed increased ROS levels nor ROS-induced damage. Apoptosis-induced proliferation and autophagy function as QC mechanisms in avian cells, which may be contribute to the longevity of birds as compared to mammals.

\section{Acknowledgements}

We are indebted to Stefan Dröse (Institute for Biochemistry I) for performing the respirometry measurements. Furthermore, we thank Sandra Loch (Goethe University Frankfurt) for performing the FACS analysis. We acknowledge gratefully the support from the EU Integrated Project "MiMage" CT 2004-512020. Sören Mai received a stipend from the Center of Membrane Proteomics Frankfurt (CMP), which is acknowledged.

\section{Appendix A. Supplementary data}

Supplementary data associated with this article can be found, in the online version, at doi:10.1016/j.mad.2009.11.005.

\section{References}

Ali, S.S., Xiong, C., Lucero, J., Behrens, M.M., Dugan, L.L., Quick, K.L., 2006. Gende differences in free radical homeostasis during aging: shorter-lived female C57BL6 mice have increased oxidative stress. Aging Cell 5, 565-567.

Barja, G., 1998. Mitochondrial free radical production and aging in mammals and birds. Ann. N. Y. Acad. Sci. 854, 224-238.

Barja, G., 2007. Mitochondrial oxygen consumption and reactive oxygen species production are independently modulated: implications for aging studies. Rejuvenation Res. 10, 215-224.

Barja, G. Herrero, A, 1998. Localization at complex I and mechanism of the highe free radical production of brain nonsynaptic mitochondria in the short-lived rat than in the longevous pigeon. J. Bioenerg. Biomembr. 30, 235-243.

Barja, G., Cadenas, S., Rojas, C., Perez-Campo, R., Lopez-Torres, M., 1994. Low mitochondrial free radical production per unit $\mathrm{O}_{2}$ consumption can explain the simultaneous presence of high longevity and high aerobic metabolic rate in birds. Free Rad. Res. 21, 317-328.

Chabi, B., Ljubicic, V., Menzies, K.J., Huang, J.H., Saleem, A., Hood, D.A., 2008 Mitochondrial function and apoptotic susceptibility in aging skeletal muscle. Aging Cell 7, 2-12.

Chaudhuri, A.R., de Waal, E.M., Pierce, A, Van Remmen, H., Ward, W.F., Richardson, A., 2006. Detection of protein carbonyls in aging liver tissue: a fluorescencebased proteomic approach. Mech. Ageing Dev. 127, 849-861.

Cheng, Y., Qiu, F., Guo, Z.M., Tashiro, S.I., Onodera, S., Ikejima, T.Y., 2009. Autophagy inhibits reactive oxygen species-mediated apoptosis via activating p38-nuclear factor-kappa B survival pathways in oridonin-treated murine fibrosarcoma L929 cells, FEBS J., January 24 [Epub ahead of print].

Cohen, A.A., McGraw, K.J., Wiersma, P., Williams, J.B., Robinson, W.D., Robinson, T.R. Brawn, J.D., Ricklefs, R.E., 2008. Interspecific associations between circulatin antioxidant levels and life-history variation in birds. Am. Nat. 172, 178-193.

Dimri, G.P., Lee, X., Basile, G., Acosta, M., Scott, G., Roskelley, C., Medrano, E.E. Linskens, M., Rubelj, I., Pereira-Smith, O., 1995. A biomarker that identifies senescent human cells in culture and in aging skin in vivo. Proc. Natl. Acad. Sci. U.S.A. 92, 9363-9367.

Dufour, E., Larsson, N.G., 2004. Understanding aging, revealing order out of chaos. Biochim. Biophys. Acta 1658, 122-132.

Fan, Y., Bergmann, A., 2008. Apoptosis-induced compensatory proliferation. The Cell is dead. Long live the Cell! Trends Cell Biol. 18, 467-473.

Federspiel, M.J., Hughes, S.H., 1997. Retroviral gene delivery. Methods Cell Biol. 52 179-214.

Harman, D.J., 1972. The biologic clock: the mitochondria? Am. Geriatr. Soc. 20, 145 147

Hayashi, Y., Yoshida, M., Yamato, M., Ide, T., Wu, Z., Ochi-Shindou, M., Kanki, T., Kang, D., Sunagawa, K., Tsutsui, H., Nakanishi, H., 2008. Reverse of age-dependent memory impairment and mitochondrial DNA damage in microglia by an overexpression of human mitochondrial transcription factor a in mice. J. Neurosci. 28, 8624-8634.
Herrero, A., Barja, G., 1999. 8-Oxo-deoxyguanosine levels in heart and brain mitochondrial and nuclear DNA of two mammals and three birds in relation to their different rates of aging. Aging (Milano) 11, 294-300.

Holmes, D.J., Ottinger, M.A., 2003. Birds as long-lived animal models for the study of aging. Exp. Gerontol. 38, 1365-1375.

Holmes, D.J., Austad, S.N., 1995. Birds as animal models for the comparative biology of aging: a prospectus. J. Gerontol. A. Biol. Sci. Med. Sci. 50, B59-B66.

Hutter, E., Unterluggauer, H., Garedew, A., Jansen-Durr, P., Gnaiger, E., 2006. Highresolution respirometry-a modern tool in aging research. Exp. Gerontol. 41 103-109.

Jendrach, M., Pohl, S., Vöth, M., Kowald, A., Hammerstein, P., Bereiter-Hahn, J., 2005. Morpho-dynamic changes of mitochondria during ageing of human endothelial cells. Mech. Ageing Dev. 126, 813-821.

Jendrach, M., Mai, S., Pohl, S., Vöth, M., Bereiter-Hahn, J., 2008. Short-long-term alterations of mitochondrial morphology, dynamics and mtDNA after transient oxidative stress. Mitochondrion 8, 293-304.

Kiffin, R., Bandyopadhyay, U., Cuervo, A.M., 2006. Oxidative stress and autophagy Antioxid. Redox Signal. 8, 152-162.

Ko, H., Kim, Y.J., Park, J.S., Park, J.H., Yang, H.O., 2009. Autophagy inhibition enhances apoptosis induced by ginsenoside Rk1 in hepatocellular carcinoma cells. Biosci. Biotechnol. Biochem. 73, 2183-2189.

Ku, H.H., Sohal, R.S., 1993. Comparison of mitochondrial pro-oxidant and antioxidant defenses between rat and pigeon: possible basis of variation in longevity and metabolic potential. Mech. Ageing Dev. 72, 67-76.

ansdorp, P.M., Verwoerd, N.P. van de Rijke, F.M., Dragowska, V. Little, M.T. Dirks, R.W., Raap, A.K., Tanke, H.J., 1996. Heterogeneity in telomere length of human chromosomes. Hum. Mol. Genet. 5, 685-691.

Lu, T., Finkel, T., 2008. Free radicals and senescence. Exp. Cell. Res. 314, 1918 1922.

Mai, S., Wiener, F., In Beatty, B., Mai, S., Squire, J. (Eds.), 2002. FISH: A Practical Approach. Oxford University Press, Oxford, pp. 55-76.

Milán, M., Campuzano, S., García-Bellido, A., 1997. Developmental parameters of cell death in the wing disc of Drosophila. Proc. Natl. Acad. Sci. U.S.A. 94, 56915696.

Mysore, T.B., Shinkel, T.A., Collins, J., Salvaris, E.J., Fisicaro, N., Murray-Segal, L.J. Johnson, L.E., Lepore, D.A., Walters, S.N., Stokes, R., Chandra, A.P., O'Connell, P.J., d'Apice, A.J., Cowan, P.J., 2005. Overexpression of glutathione peroxidase with two isoforms of superoxide dismutase protects mouse islets from oxidative injury and improves islet graft function. Diabetes 54, 2109-2116.

Ogburn, C.E., Austad, S.N., Holmes, D.J., Kiklevich, J.V., Gollahon, K., Rabinovitch, P. Martin, G.M., 1998. Cultured renal epithelial cells from birds and mice: enhanced resistance of avian cells to oxidative stress and DNA damage. J. Gerontol. Biol. Sci. 53A, B287-B292.

Ogburn, C.E., Carlberg K. Ottinger, M.A., Holmes, D.J., Martin, G.M., Austad, S.N 2001. Exceptional resistance to oxidative damage in long-lived birds requires active gene expression. J. Gerontol. Biol. Sci. 56, B468-B474.

Orr, W.C., Sohal, R.S., 1994. Extension of life-span by overexpression of superoxde dismutase and catalase in Drosophila melanogaster. Science 263, 1128 1130.

Passos, J.F., Saretzki, G., Ahmed, S., Nelson, G., Richter, T., Peters, H., Wappler, I. Birket, M.J., Harold, G., Schaeuble, K., Birch-Machin, M.A., Kirkwood, T.B., von Zglinicki, T., 2007. Mitochondrial dysfunction accounts for the stochastic heterogeneity in telomere-dependent senescence. PLoS Biol. 5, e110.

Perez-Campo, R., Lopez-Torres, M., Cadenas, S., Rojas, C., Barja, G., 1998. The rate of free radical production as a determinant of the rate of aging: evidence from the comparative approach. J. Comp. Physiol. B 168, 149-158.

Percy, C.J., Brown, L., Power, D.A., Johnson, D.W., Gobe, G.C., 2009. Obesity and hypertension have differing oxidant handling molecular pathways in agerelated chronic kidney disease. Mech. Ageing Dev. 130, 129-138.

Rattan, S.I., Buchanan, J.H., 1982. Optimum conditions for growth and longevity of chick embryo fibroblasts in culture. Mech. Ageing Dev. 19, 1-4.

Rezvani, H.R., Mazurier, F., Cario-André, M., Pain, C., Ged, C., Taïeb, A., de Verneuil, H. 2006. Protective effects of catalase overexpression on UVB-induced apoptosis in normal human keratinocytes. J. Biol. Chem. 281, 17999-18007.

Santos, J.H., Mandavilli, B.S., Van Houten, B., 2002. Measuring oxidative mtDNA damage and repair using quantitative PCR. Methods Mol. Biol. 197, 159-176.

Sasaki, T., Unno, K., Tahara, S., Shimada, A., Chiba, Y., Hoshino, M., Kaneko, T., 2008. Age-related increase of superoxide generation in the brains of mammals and birds. Aging Cell 7, 459-469.

Senthil, V., Kumaran, Arulmathi, K., Srividhya, R., Kalaiselvi, P., 2008. Repletion of antioxidant status by EGCG and retardation of oxidative damage induced macromolecular anomalies in aged rats. Exp. Gerontol. 43, 176-183.

Simonsen, A. Cumming R.C. Brech, A, Isakson, P. Schubert, D. R, Finley, K. D., 2008. Promoting basal levels of autophagy in the nervous system enhances longevity and oxidant resistance in adult Drosophila. Autophagy 4, 176-184.

Stolzing, A., Jones, E., McGonagle, D., Scutt, A., 2008. Age-related changes in human bone marrow-derived mesenchymal stem cells: consequences for cell therapies. Mech. Ageing Dev. 129, 163-173.

Tatsuta, T., Langer, T., 2008. Quality control of mitochondria: protection against neurodegeneration and ageing. EMBO J. 27, 306-314.

Trifunovic, A., Wredenberg, A., Falkenberg, M., Spelbrink, J.N., Rovio, A.T., Bruder, C.E., Bohlooly-Y, M., Gidlof, S., Oldfors, A., Wibom, R., Tornell, J., Jacobs, H.T., Larsson, N.G., 2004. Premature ageing in mice expressing defective mitochondrial DNA polymerase. Nature 429, 417-423.

Trifunovic, A., Hansson, A., Wredenberg, A., Rovio, A.T., Dufour, E., Khvorostov, I. Spelbrink, J.N., Wibom, R., Jacobs, H.T., Larsson, N.G., 2005. Somatic mtDNA 
mutations cause aging phenotypes without affecting reactive oxygen species production. Proc. Natl. Acad. Sci. U.S.A. 102, 17993-17998.

Unterluggauer, H., Hütter, E., Voglauer, R., Grillari, J., Vöth, M., Bereiter-Hahn, J., Jansen-Dürr, P., Jendrach, M., 2007. Identification of cultivation-independent markers of human endothelial cell senescence in vitro. Biogerontology 8 , 383-397.
Valentin-Vega, Y.A., Okano, H., Lozano, G., 2008. The intestinal epithelium compensates for p53-mediated cell death and guarantees organismal survival. Cell Death Differ. 15, 1772-1781.

Young, A.R.J., Narita, M., Ferreira, M., Kirschner, K., Sadaie, M., Darot, J.F.J., Tavare, S., Arakawa, S., Shimizu, S., Watt, F.M., Narita, M., 2009. Autophagy mediates the mitotic senescence transition. Genes Dev. 23, 798-803. 